Check for updates

The BMJ

Cite this as: BMJ 2021;375:n3088 http://dx.doi.org/10.1136/bmj.n3088 Published: 15 December 2021

\title{
Doctors are under more work pressure than during height of covid-19 pandemic in 2020
}

\section{Ingrid Torjesen}

The pressures on doctors generated by the covid-19 pandemic have worsened during 2021 and this will have repercussions for doctors' welfare, patient safety, and workforce retention, the General Medical Council has warned.

The growing backlog of patient care amid repeated waves of covid-19 means more doctors are struggling with their workload, this year's GMC annual report said, after some reported experiencing "a temporary decrease in workload" during $2020{ }^{1}$

Charlie Massey, the GMC’s chief executive, said, “The pandemic has had the effect of pressing 'fast forward' on what was already a precarious situation.

"We're seeing exhaustion and dissatisfaction returning to levels that are bad for doctors and bad for patients. We need a shift of mindset in the way doctors, nurses, and other healthcare professionals work together or there could be far reaching consequences for patient safety."

The barometer survey of a representative sample of 3386 UK doctors, commissioned by the GMC, found that GPs face the greatest workforce pressure of any group of doctors. On average, GPs described three quarters of their days as "high intensity" and around a third are considered at high risk of burnout-almost double the proportion at risk across the profession as a whole.

The proportion of GPs and specialists struggling with their workload doubled in 2021, with more than half of GPs (54\%) and almost three out of 10 specialists (28\%) now falling into this group.

A growing number of doctors have taken "hard steps" towards leaving the profession, such as making enquiries about a career change or applying for a role. The proportion doing this was $3 \%$ in 2019, $4 \%$ in 2020 , and $7 \%$ in 2021 , with $81 \%$ of those planning to leave for reasons other than retirement, citing the impact of work on their wellbeing as a factor.

Doctors belonging to minority groups are more likely to be planning to leave. Doctors with disabilities were almost twice as likely as non-disabled doctors to be dissatisfied, at a high risk of burnout, struggling with workload, and taking steps towards leaving the profession. And doctors from a minority ethnic background were twice as likely as white doctors $(10 \% v 5 \%)$ to be planning to leave.

Doctors from ethnic minorities, particularly Asian and British Asian doctors, were more likely to say they felt unsupported by their immediate colleagues or did not feel part of a supportive team.

Some positive changes to working practices resulting from the pandemic, most notably improved teamworking with other health professionals, were reported by doctors. "Despite the difficulties, doctors still feel the pandemic has led to positive changes, particularly in relation to visible leadership, teamwork, high quality training environments, and knowledge sharing across the profession," Massey said. "It is crucial that we embed and build on these benefits in the months ahead."

Bringing medical associate professionals, such as physician associates and anaesthesia associates, within regulation would enable them to be deployed to help tackle workforce challenges, he added.

1 General Medical Council. The state of medical education and practice in
the UK. December 2021. www.gmc-uk.org/about/what-we-do-and-
why/data-and-research/the-state-of-medical-education-and-practice-in-
the-uk

This article is made freely available for use in accordance with BMJ's website terms and conditions for the duration of the covid-19 pandemic or until otherwise determined by BMJ. You may use, download and print the article for any lawful, non-commercial purpose (including text and data mining) provided that all copyright notices and trade marks are retained. 